\title{
ENFERMAGEM: REALIDADE E PERSPECTIVA NA ASSISTÊNCIA E NO GERENCIAMENTO*
}

\author{
Eliete Maria Silva** \\ Elizabeth Laus Ribas Gomes***

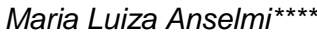

\begin{abstract}
As autoras buscam discutir as atividades desenvolvidas pela enfermagem sob duas orientações gerais: a da assistência e do gerenciamento, no que diz respeito ao concreto do trabalho e às perspectivas desse mesmo trabalho e ás perspectivas desse mesmo trabalho.

Assim, polemizam a dicotomia criada em torno da função administrativa versus assistencial e chamam a atenção para a impossibilidade de se pensar o trabalho de enfermagem de forma desarticulada das diversas práticas em saúde, que no conjunto complementam-se para atender às necessidades de saúde da população a nível social.
\end{abstract}

Este tema é bastante oportuno e se reveste de grande importância, principalmente nesse momento em que se percebe uma insatisfação, por parte das enfermeiras em seu trabalho cotidiano, concomitantemente a um movimento que busca mudança nesse mesmo trabalho, ou seja: um movimento de mudança, pela insatisfação. "Recentemente, a partir dos anos 80, a enfermeira passa a questionar sua posição na equipe de saúde, no modelo de saúde vigente e na sociedade em geral e alguns estudos vêm buscando a compreensão do trabalho da enfermagem enquanto exercício institucionalizado de diversas categorias profissionais e que se relaciona e se articula com outras práticas sociais, em um dado tempo e em determinada formação sócio-econômica e cultural". (SILVA, 1991, p. 14). Entendemos, portanto, que esta temática possibilita uma discussão a respeito do que é assistência na enfermagem e o que é o gerenciamento na enfermagem ou a atividade gerencial na enfermagem.

Trataremos primeiramente daquilo que entendemos como real no trabalho de enfermagem, para a seguir expor aquilo que vemos como perspectiva para este trabalho.

$\mathrm{Na}$ realidade de hoje podemos afirmar que: "no trabalho da enfermagem, é possível aprender duas orientações gerais para as atividades desenvolvidas: a primeira diz respeito ao cuidado, à assistência direta ( exercida por todos os elementos da equipe de enfermagem, especialmente pelos atendentes e auxiliares), a

*Conferência proferida no IV Encontro de Enfermagem do Oeste Paulista realizado de 21 a 24 de agosto de 1991, em São José do Rio Preto - São Paulo.

**Professora Assistente do Departamento de Enfermagem Materno-Infantil e Saúde Pública da Escola de Enfermagem de Ribeirão Preto da Universidade de São Paulo.

***Professora Doutora do Departamento de Enfermagem Geral e Especializada da Escola de Enfermagem de Ribeirão Preto da Universidade de São Paulo.

****Professora Assistente do Departamento de Enfermagem Geral e Especializada da Escola de Enfermagem de Ribeirão Preto da Universidade de São Paulo. 
segunda relaciona-se com a organização do serviço de enfermagem e da saúde como um todo (exercida pelos vários elementos mas, predominantemente pela enfermeira)". (SILVA, 1991, p. 615). E isso desde que a enfermagem se institucionalizou, já no século XIX.

Essas duas orientações não se constituem em pólos opostos do trabalho de enfermagem mas, ao contrário, fazem parte de um mesmo processo de trabalho. A dicotomia entre o administrar e assistir não advém da prática e sim de um discurso acadêmico aqui entendido como uma discussão teórica proveniente de academia, da produção "científica", que não tem se apoiado e nem se legitima na realidade do trabalho de enfermagem e da saúde como um todo. A academia coloca a atividade administrativa e do gerenciamento como um desvio de função, a partir da pressuposta idéia de que as funções da enfermeira seriam aquelas relacionadas diretamente com o cuidado ao paciente. $E$ aqui enfatizamos que não há como negar que a assistência, o cuidado à pessoa humana seja inerente à enfermagem. Mas será também inerente à enfermeira? Vamos analisar mais vagarosamente a respeito dessa questão.

Quando o hospital começou a se construir em um espaço de cura a conseqüentemente um local de trabalho, de concentração tecnológico, iniciou-se a fragmentação do alto clínico em numerosas práticas especializadas. Assim, os estabelecimentos hospitalares passaram a construir, na sociedade brasileira, o maior mercado de trabalho para as enfermeiras, principalmente a partir da década de 50. O hospital começou a tomar feições de uma organização complexa e a requerer um envolvimento cada vez maior da enfermeira em atividades gerenciais. Em conseqüência, o preparo de pessoal passou a ser cada vez mais objeto de atenção e transformação e a administração ganhou impulso e valorização na enfermagem. Corroborando esta questão, CARRASCO(1989) encontrou que nas décadas de 50 e 60, houve uma considerável produção científica envolvendo a temática de administração a qual se referia à organização do serviço de enfermagem hospitalar, com ênfase nos princípios gerais de administração como: planejamento, organização, direção, coordenação e controle. Já naquela época d Divisão de Educação da Associação Brasileira de Enfermagem (ABEn) começou a estabelecer planos para organizar cursos para a formação de enfermeiros chefes e instrutores, tendo em vista a organização dos vários serviços do hospital (RIBAS-GOMES, 1991, p. 93).

Na época o discurso da Associação Brasileira de Enfermagem era no sentido da necessidade de dar às alunas conhecimento de administração para atuarem como enfermeiras-chefes.

A partir da década de 70 observa-se uma tendência cada vez maior para o atendimento especializado nos grandes centros urbanos, onde se começou a organizar e implantar os Centros ou Unidades de Terapia Intensiva. Correspondentemente a oferta de serviços para a enfermeira, na área hospitalar, sofreu um aumento considerável não só pelo crescente grau de especialização na prática médica, a qual passou a necessitar de mais pessoal de enfermagem, mas também pela expansão da medicina capitalista baseada na formação de um complexo médico-empresarial.

Nessa dinâmica exacerbaram-se as atividades de organização e planejamento dos serviços e ainda de supervisão do pessoal auxiliar através da enfermeira, ou seja, algumas funções administrativas ligadas principalmente à gerência de unidades, como por exemplo, escala mensal e distribuição de tarefas diárias ao pessoal auxiliar, controle de materiais e equipamento etc.

Nessa mesma década, surge na enfermagem 0 discurso idealizado do "desvio de função" da enfermeira, da busca da autonomia profissional e da polêmica criada em torno da administração versus assistência. Esse discurso, desvinculado do cotidiano profissional, veio apoiar-se e justificar-se nas teorias de enfermagem que começaram a ser desenvolvidas pelas teoristas americanas e, no Brasil, por Wanda de Aguiar Horta, através de sua principal obra intitulada Processo de Enfermagem, publicada em 1979.

Enquanto as teorias de enfermagem ultrapassaram, no nível discursivo, o saber técnico (assistencial) e administrativo (gerencial) - principais instrumentos de trabalho de enfermeira - "indo centrar-se principalmente, nos aspectos adaptação psicológica do homem"(ALMEIDA \& ROCHA, p. 114), entretanto, na prática não possibilitaram a conquista idealizada da autonomia profissional, pois parece ter sido uma mais voltada para as questões acadêmicas da enfermagem, sem dar 
conta de contemplar a dinâmica dos serviços.

Quanto à teoria de Wanda Horta, "sua idéia de garantir a autonomia profissional somente através de uma sistematização das ações, se mostra ideologizada quando identificamos outros determinantes não considerados por Wanda Horta e que interferem em tal autonomia, como o mercado de trabalho disponível, a relação com outros profissionais e ocupacionais que atuam na assistência à saúde, a estrutura organizacional e política dos setores da saúde e educação e também a própria estrutura com suas relações econômicas, políticas e ideológicas" (RIBAS-GOMES \& SILVA, 1989, p. 33). E ainda como "poderiam os atendentes ou mesmo as enfermeiras desenvolver as teorias no cuidado ao paciente, sendo que o trabalho na saúde é coletivo, centrado nas funções e sem muita complementaridade, acrescido da figura do administrador ou superintendente, que simboliza a organização formal do trabalho explícito na racionalidade e rentabilidade econômica através da prestação de bens de saúde?" (ALMEIDA \& ROCHA, 1986, p. 114).

Assim sendo, a polêmica criada em torno da autonomia profissional e da função administrativa versus assistencial é um projeto acrítico, na medida em que não considera a constituição de um mercado de trabalho centrado em um modelo de atenção à saúde que privilegia a relação individual médico-paciente, com destaque para o corpo humano, numa perspectiva físio-patológica. Modelo no qual a enfermeira é o agente necessário, em escala social, para viabilizar e facilitar a relação individual médico-paciente, através do gerenciamento do "espaço" onde essa relação acontece.

Essa posição, entretanto, não é confortável para a enfermeira, por duas razões básicas:

01) Não existe um instrumental próprio que possibilite à enfermeira administrar. Ela utiliza para tal um saber advindo da Administração Geral;

02) O serviço de enfermagem fica entre a autoridade de uma administração superior e entre a autoridade técnica do médico.

Dessa forma o planejamento de serviço emana de instâncias superiores, cabendo à enfermeira principalmente a execução de normas. A enfermeira tem sido a profissional que viabiliza as normas e rotinas do serviço e ainda coordena outros serviços (os chamados de apoio). Essas atividades são uma realidade do trabalho de enfermeira, instrumentalizado basicamente pela administração, viabilizando assim a assistência à saúde.

Ainda em torno da discussão administração versus assistência parecer haver, na atualidade, uma tendência em reconhecer no exercício profissional a atividade administrativa. Contudo, mais uma vez, esta não é pensada/percebida de forma articulada com o trabalho coletivo em saúde, mas sim em relação à sistematização da assistência de enfermagem. Num plano bastante ideológico - advindo originalmente da academia - a realidade do trabalho é tida como aquela que permite à enfermeira administrar a "assistência de enfermagem". Nesse sentido, o conhecimento que precisaria instrumentalizar o trabalho estaria nos diversos modelos assistenciais, como por exemplo, o de Wanda Horta.

Essa possibilidade parecer existir em unidades fechadas e altamente especializadas, onde a enfermeira presta assistência direta. Mas tal representa uma parcela pequena do trabalho, não devendo ser encarada como uma possibilidade ampla e genérica. Tomando a enfermagem em geral, ela é parte do trabalho em saúde, de forma que a assistência de enfermagem tem relações sociais com as outras práticas de saúde, que no conjunto complementam-se. Portanto, a enfermagem não desenvolve um trabalho autônomo, tanto no que se refere ao cuidar, quanto ao administrar, pois essa autonomia fica submetida a instâncias hierarquicamente superiores - para o administrar - e ao médico - para cuidado clínico, pois é ele quem possui os instrumentos para diagnosticar e estabelecer ações terapêuticas, as quais direcionam parte significativa do cuidado em enfermagem.

E quanto às perspectivas da enfermagem na assistência e no gerenciamento?

Com as propostas de reorganização dos serviços de saúde, advindas do novo pensamento sanitário (implantação do Sistema Unificado e Descentralizado de Saúde, na perspectiva do Sistema Único de Saúde - SUS), vêm-se tentando "reformular os conteúdos programáticos dos Cursos de Saúde Pública, criar novos cursos de Gestão e Planejamento de Sistema de Saúde transformando-os, centralmente, em instrumentos de formação de um novo especialista: o administrador sanitário, profissional que deverá 
dominar tanto os tradicionais conhecimentos de Saúde Pública, com a habilidade de gerenciar, planejar e organizar os serviços de saúde na busca de uma sempre maior capacidade de resolver os problemas da área, lidando com todo o complexo de determinantes desses processos" (CAMPOS, 1989, p. 29).

Então, com a implantação do SUS, o que muito tem se discutido é a questão da gerências de serviços de saúde, a capacidade desses serviços para resolver os problemas da área, enfim, como gerenciar, planejar e organizar tais serviços, tanto hospitalares quanto de unidades básicas, no esforço de se conseguir uma programação/organização que alcance o controle dos processos saúde-doença da população através, principalmente de vigilância epidemiológica articulada com a assistência individual. Nesse sentido acreditamos haver uma possibilidade de instrumentalização da prática de enfermagem com base na gerência de serviços, tanto a nível hospitalar como de saúde pública.

Para tanto as questões de desenvolvimento de pessoal e da educação continuada devem pautar "em metodologia que permita a análise crítica da realidade e a oportunidade de construção de novas formas de atuar... tendo que ser considerada como parte de uma política global de qualificação dos trabalhos de saúde, centrada nas necessidades de transformação de práticas fundamentais para o alcance dos princípios contidos na Reforma Sanitária Brasileira" (BRASIL, Ministério da Saúde, 1990, p. 10).

O novo modelo assistencial, que vem sendo implementado, demanda um profissional crítico, que além da competência técnica também dê conta da dimensão política do trabalho no setor de saúde, e que além das questões biológicas e individuais, busque compreender e assistir aos homens, mulheres e crianças em suas dimensões sociais, econômicas, culturais, familiares, afetivas, verdadeiramente humanas, com intuito de desenvolver um serviço que atenda às necessidades de saúde e contribui com o fortalecimento da cidadania e democracia brasileiras.

The authors discuss the activities developed by Nursing in two general orientations: the assistance and the management, concerning the concrete work and its perspectives.

Therefore, they engage in polemics around the administrative versus assistance functions and attract the attention to the impossibility of thinking the nursing work unarticulated of different health practices, as a woole they accomplish each other in attempting the necessities of health of the population in a social level.

Las autoras buscan discutir las actividades desarrolladas por le enfermería bajo dúos orientadores generales: la asistencia y la gerencia, a respecto del trabajo concreto y sus perspectivas.

Así, polemizan la dicotomía creada al redor de la función administrativa versus la asistencial y chaman la atención para la imposibilidad de pensarse lo trabajo de enfermería desarticulado de las diversas prácticas en salud, que en su conjunto complementase para atender a las necesidades de salud de la población a nivel social.

\section{REFERÊNCIAS BIBLIOGRÁFICAS}

01. ALMEIDA, M. C. P.; ROCHA, J. S. Y. O saber de enfermagem e sua dimensão prática. São Paulo: Cortez, 1986.

02. BRASIL. Ministério da Saúde. A educação continuada de enfermeiros no sistema único de saúde. Brasília: Ministério da Saúde/Secretaria de Modernização Administrativa e recursos Humanos, 1990.

03. CAMPOS, G. W. de S. Planejamento sem normas. Campinas: HUCITEC, 1989. p. 09-31: Considerações sobre o processo de administração e gerência de serviços de saúde. 
04. CARRASCO, M. A. P. Influência das escolas de administração científica e clássica na produção científica da enfermagem brasileira. Ribeirão Preto, Universidade de São Paulo, 1987.

05. HORTA, W. de A. Processos de Enfermagem. São Paulo: EPU: Ed. Universidade de São Paulo, 1979. p. 99.

06. RIBAS-GOMES, E. L.; Silva, E. M. Determinação histórico-social da produção científica de Wanda de Aguiar Horta. In: SEMANA WANDA DE AGUIAR HORTA, 3.,1989, São Paulo. Anais. São Paulo: Escola de Enfermagem de Ribeirão Preto, Universidade de São Paulo, 1989. p. 31-46.

07. RIBAS-GOMES, E. L., Administração em enfermagem: constituição histórico-social do conhecimento. Ribeirão Preto. p. 188. Tese (Doutorado) - Escola de Enfermagem de Ribeirão Preto, Universidade de São Paulo, 1991.

08. SILVA, E. M. Supervisão em Enfermagem: análise crítica das publicações no Brasil dos anos 30 à década de 80. Ribeirão Preto. p. 158. Dissertação (Mestrado) - Escola de Enfermagem de Ribeirão Preto, Universidade de São Paulo, 1991. 